\title{
Anabases
}

ANABASES Traditions et réceptions de l'Antiquité

$25 \mid 2017$

Varia

\section{PROCOPE DE CÉSAREE, Histoire des Goths}

\section{Olivier Gengler}

\section{(2) OpenEdition \\ Journals}

Édition électronique

URL : https://journals.openedition.org/anabases/6150

DOI : 10.4000/anabases.6150

ISSN : 2256-9421

\section{Éditeur}

E.R.A.S.M.E.

\section{Édition imprimée}

Date de publication : 1 avril 2017

Pagination : 297-298

ISSN : 1774-4296

\section{Référence électronique}

Olivier Gengler, « Procope de césaree, Histoire des Goths », Anabases [En ligne], 25 | 2017, mis en ligne le 01 avril 2017, consulté le 15 février 2023. URL : http://journals.openedition.org/anabases/6150 ; DOI : https://doi.org/10.4000/anabases.6150

Ce document a été généré automatiquement le 19 janvier 2021.

\section{(c) (i) $९$}

Creative Commons - Attribution - Pas d'Utilisation Commerciale - Pas de Modification 4.0 International - CC BY-NC-ND 4.0

https://creativecommons.org/licenses/by-nc-nd/4.0/ 


\title{
PROCOPE DE CÉSAREE, Histoire des Goths
}

\author{
Olivier Gengler
}

\section{RÉFÉRENCE}

PROCOPE DE CÉSAREE, Histoire des Goths, texte traduit par Denis Roques †, présenté, révisé et annoté par Janick Auberger, 2 t., Paris, Les Belles Lettres, "La Roue à livres ", 2015, LXXVIII + $366+420$ p., 45 euros / ISBN 978-2-251-33976-4

1 Avec ces deux volumes consacrés à la guerre contre les Goths, c'est-à-dire les livres V à VIII des Guerres de Justinien, la publication aux éditions des Belles Lettres de la traduction des œuvres de Procope de Césarée (ca. 500-560 ap J.-C.) franchit une nouvelle étape après l'Histoire Secrète (P. Maraval, 1989) et les livres III et IV des Guerres consacrés à la campagne contre les Vandales (D. Roques, 1990). C'est à Janick Auberger que l'on doit d'avoir préparé ce volume pour la publication après le décès de Denis Roques qui en avait entrepris la réalisation. La tâche n'était certainement pas aisée et l'on peut louer J. Auberger de l'avoir menée à bien, pour que le fruit du labeur de Denis Roques soit livré au public accompagné des éclaircissements nécessaires pour rendre le texte intelligible. Une introduction bien informée brosse rapidement le contexte historique et met au clair les questions qui se posent sur l'œuvre et son auteur. Le portrait de Procope en historien ( $\mathrm{p}$.XVII-XXIV) est nuancé et fort complet, même si l'on ne suivra pas J. Auberger dans ses réflexions (p. XXIII) sur le fait que l'auteur ne souhaitait pas chercher « l'ensemble de la documentation disponible sur telle ou telle région " ou faisait " peu de cas (...) des considérations économiques, sociales ou religieuses ", qui sont totalement anachroniques. Mais très justement, l'imitation de Thucydide par Procope, qui invite parfois les modernes à négliger la contribution de ce dernier, est ici mise en perspective pour faire ressortir les qualités propres de l'auteur des Guerres : " le talent de Procope va bien au-delà d'une pâle imitation » (p. XLIX). La traduction de D. Roques, revue par J.Auberger, est élégante et fidèle, et rend admirablement bien la prose de Procope. Les notes, glossaire, cartes et index aident le lecteur peu familier de l'histoire du règne de Justinien et de l'œuvre de Procope à 
trouver son chemin. On pourra regretter un certain nombre de coquilles et d'erreurs qui viennent déparer ces beaux volumes, la plupart anodines (par exemple l'oubli du numéro de livre dans la référence à I, 21, 3-12 p. XXVII ou PLRE IIa pour IIIa, p. LIX), quelques-unes plus graves, comme la traduction de Comes domus divinae par "Comte des maisons divines " (p.LXXVI, où la description de cette charge est également insuffisante) ou des contradictions d'une note à l'autre (ainsi t. I, p. 310-311, n. 163 et 168 ; t. II, p. 354-355, les n. 116 et 120 se répètent inutilement). Mais c'est là la seule critique que l'on peut adresser à ces volumes qui livrent à un large public une œuvre jusque-là peu accessible en français, et que l'on espère voir bientôt disponible en son entier, puisque à ce jour manque la seule traduction des livres I et II des Guerres relatant les conflits contre les Perses (une traduction commentée des Constructions par Denis Roques a été publiée après son décès par E. Amato et J. Schamp : Procope de Césarée, Constructions de Justinien Ir, Alessandria 2011 [Hellenica 39]).

\section{AUTEURS}

\section{OLIVIER GENGLER}

Académie des Sciences de Heidelberg / Université de Tübingen

ogengler@yahoo.fr 